\title{
ENGAJAMENTO E CRÍTICA SOCIAL AO RACISMO NA SOCIEDADE ESTADUNIDENSE NO DOCUMENTÁRIO “EU NÃO SOU SEU NEGRO”.
}

\author{
Michel Gomes da Rocha ${ }^{75}$
}

\begin{abstract}
Resumo: A resenha crítica analisa o documentário "Eu não sou seu negro”, que possui direção do cineasta haitiano Raoul Peck. A produção se debruça sobre um projeto inacabado do romancista, ensaísta, dramaturgo, poeta e crítico social estadunidense James Baldwin. A narrativa possui uma montagem cinematográfica em capítulos e três níveis, são eles: a escrita de Lembremse desta casa (livro que inspira o roteiro do documentário apresentado através de narrador Over), o engajamento de Baldwin para além de suas obras, em falas publicas, e o contexto atual como materialização do diagnostico dado pelo crítico.
\end{abstract}

Palavras-chave: James Baldwin; Crítica ao Racismo; Engajamento.

\section{Engagement and Social Critique of Racism in the US Society in the documentary "I am not your Negro".}

\begin{abstract}
The critical review analyzes the documentary "I am not your negro" with direction of the Haitian filmmaker Raoul Peck. The production focuses on an unfinished project of the American novelist, essayist, playwright, poet and social critic James Baldwin. The narrative has a cinematographic montage in chapters and three levels, they are: the writing of Remember this house (book that inspires the script of the film presented through narrator Over), the engagement of Baldwin beyond his works, in speech and the current context as a materialization of the diagnosis given by the critic.
\end{abstract}

Keywords: James Baldwin; Critique of Racism; Engagement.

Em junho de 1979, o aclamado escritor James Baldwin ${ }^{76}$ se empenhou em um projeto complexo, contar a história dos Estados Unidos de forma peculiar, através da história de vida de três amigos, grandes nomes do movimento pelos direitos civis que foram assassinados; Medgar Evers (1925-1963), Martin Luther King Jr. (1929-1968) e Malcolm X (1925-1965). O escrito, ainda em

75 Doutorando em História Econômica na FFLCH - Faculdade de Filosofia, Letras e Ciências Humanas da Universidade de São Paulo. Bolsista FAPESP (Fundação de Amparo à Pesquisa do Estado de São Paulo) Processo: 2018/0322-9. É também Mestre em História Social pela USP, bem como possui Licenciatura e Bacharelado em História pela Universidade Federal de Pernambuco. E-mail: michelrocha@usp.br.

76 James Arthur Baldwin (2/08/1924 - Nova Iorque; 1/12/1987 - Saint-Paul de Vence) foi um romancista, ensaísta, dramaturgo, poeta e crítico social estadunidense que possui extensa obra, escrita entre a década de 1950 até sua morte em fins dos anos 1980. São elas: Go Tell it on the Mountain (1953); Stranger in the Village (1953); The Amen Corner (1954); Notes of a Native Son (1955); Giovanni's room (1956); Sonny's Blues (1957); Nobody Knows My Name: More Notes of a Native Son (1961); Another Country (1962); The Fire Next Time (1963); Blues for Mister Charlie (1964); Going to Meet the Man (1965); Tell Me How Long the Train's Been Gone (1968); A Rap on Race (1971); No Name in the Street (1972); A Dialogue (1973); If Beale Street Could Talk (1974); The Devil Finds Work (1976); Just Above My Head (1979); The Evidence of Things Not Seen (1985); The Price of the Ticket (1985). Bem como o texto não encerrado Remember this house, objeto de nossa analise em sua versão cinematográfica. 
forma incipiente, foi chamado de "Lembrem-se desta casa" (Remember this house), e que devido a complicações de uma doença que levou Baldwin a morte não foi encerrado, sendo confiado ao amigo Raoul Peck, que torna o escrito com suas intenções (dar visibilidade as experiências vividas pelos negros na América), bem como a história de vida de Baldwin, sua percepção e militância em torno destas questões, como o roteiro de Eu não sou seu negro ${ }^{77}$.

Raoul Peck é um cineasta e ativista político haitiano nascido em 1953 que possui produção em curta e longa metragens, foi ministro da cultura no Haiti entre 1996-97, e possui obras que tocam em questões como racismo, crítica a colonialidade e desigualdade social. Obras como Canto do Haiti (1988) e Assassinato em Pacot (2014) dão luz a questões de sua terra natal. Lumumba (2000) representa o empenho de Patrice Lumumba para alcançar a independência do Congo em relação à Bélgica nos anos 1960, trata-se de um segundo esforço de Peck ao representar a trajetória do militante realizada anteriormente em Lumumba, a morte do profeta (1990). Em Abril Sangrento (2005) Peck narra a história de Augustin, um soldado que viveu o genocídio em Ruanda. Mais recentemente, Peck dirigiu uma narrativa onde reconstitui a trajetória do Jovem Karl Marx (2017). Neste sentido, a direção de Peck constitui-se como local de fala de sua militância ao problematizar questões em torno da história de vida de negros, bem como da desigualdade, seja ela social ou racial.

"Eu não sou seu negro" possui narrador Over $^{78}$ (voz de Samuel L. Jackson) e uma montagem cinematográfica em capítulos e três níveis, são eles: a narrativa de Lembrem-se desta casa, a percepção de mundo de Baldwin e experiências de vida que forjaram sua ideia de negritude, junto à conjuntura do país reconstituída para situar seu pensamento e a respectiva trajetória de seus amigos (descrita por Baldwin); a militância de Baldwin representada em suas falas na televisão, bem como em Universidades dos Estados Unidos; e por último, o contexto atual de recrudescimento que nos fornece a ideia de permanência de alguns prognósticos fornecidos por Baldwin.

Com um plano (cena) em montagem de cinema fragmentário ${ }^{79}$ (produção que se utiliza do corpus de imagem de outras obras, como uso de imagens documentais de época, nestes termos, de material já existente), de uma entrevista no The Dick Cavett Show em 1968 (momento em que houve significativa repressão em torno dos movimentos por direitos civis e os três amigos de

77 Recebeu indicações em várias premiações, no Oscar de 2017 na categoria de melhor documentário.

78 Narrador Over significa que o sujeito que narra não encena a narrativa. Existem ainda os narradores $O n$ : aquele que encena e ao ter fala a câmera o capta, bem como o Off que ao ter fala não está sendo captado no plano.

79 A técnica é também conhecida como Found Footage, bem como "filme de compilação", este ultimo termo cunhado pelo crítico Jay Leyda. 
Balwin já estavam mortos), o entrevistador indaga Baldwin sobre os progressos vividos pelos negros nos Estados Unidos, por estarem presentes em espaços como a política, no campo esportivo, em propagandas publicitárias, questionando, assim, se não há esperança de dias melhores. Baldwin sorri, pelo tom colocado por Cavett ao se referir as propagandas encenadas por negros, espaço antes inexistente. Rebate, utilizando como referência a linguagem para tratar do negro enquanto sujeito, alegando ser sua preocupação o tema do negro nesse país e seu futuro. Em um contra-plano (corte com apresentação de nova cena), visualizamos imagens do presente (Ferguson 2014), de levantes onde a comunidade negra protesta por visibilidade e respeito, fotografias objetivas são justapostas, e em uma espécie de travelling (aproximação) capta e destaca o sofrimento de jovens detidos em protestos, com uma polícia recrudescida. Em um dos cartazes entoam o lema de um dos movimentos sociais mais notáveis da atualidade:Vidas Negras importam (Black Lives Matter). ${ }^{80}$

Nesse movimento, em um novo plano, Peck traz a composição do que seria o prelúdio de Lembrem-se desta casa, onde Baldwin envia uma carta a Jay Acton da Agencia literária Spartan e narra sua percepção em torno do momento, seu aniversário de cinquenta e cinco anos e uma jornada que se aproxima, com todas as revelações que tamanha experiência pode proporcionar, escutamos o narrador, visualizando um Harlem em preto e branco. Em um contra-plano vemos um discurso do jovem Martin Luther King Jr. defendendo a desobediência civil durante o boicote aos ônibus de Montgomery, evento ocorrido em 1955 que trouxe projeção a sua militância, após a negação da costureira Rosa Parks em ceder seu lugar em um transporte publico segregado pelo Jim Crow ${ }^{81}$. Neste contexto, Baldwin situa o recorte de sua análise: o período de vidas e mortes do ponto de vista público, que vai de 1955 com a fala de King à sua morte em 1968. Seu esforço se baseia no desejo de contrapor as três vidas e que estas se revelem mutuamente.

Peck divide a narrativa em capítulos, chamando o primeiro de "Cumprindo o meu dever", o

80 O Black Lives Matter foi criado em 2013 após a absolvição do segurança que matou o adolescente de 17 anos Trayvon Martin. Seus militantes tem denunciado e se mobilizado em diversos outros casos de violência em torno da comunidade negra no país. Ver: http://www.blacklivesmatterdmv.org/

81 O Jim Crow se compunha de leis e medidas segregacionistas que limitavam o acesso do negro estadunidense a serviços, bens e usufruto dos mesmos locais que sujeitos brancos. Tal medida se amparou em uma brecha da $14^{\circ}$ Emenda à Constituição que assegurava direitos de cidadania e sufrágio, desta forma, ao prover os mesmos serviços e oportunidades foi permitida a segregação entre as raças. Todavia, o oferecimento destes serviços se dava de forma muito inferior à comunidade negra. Extensa literatura aborda o tema, a titulo de citação aqui se dispõem casos exemplares: WOODWARD, C. Vann. The Strange Carrer of Jim Crow. New York: Oxford University Press, 1974; PACKARD, Jerrold M. American Nightmare: the history of Jim Crow. New York: St. Martin's Press, 2002; OMI, Michael; WINANT, Howard. "Racial Formations". Racial Formation in the United States: From the 1960s to the 1990s, Routledge, 1994; PLUMMER, Brenda Gayle. (Edit.) Window on freedom; Race, civil rights, and Foreign Affairs, 1945-1988. The University of North Carolina Press, Chapel Hill and London, 2003; WACQUANT, Loïc. Da escravidão ao encarceramento em massa: repensando a "questão racial” nos Estados Unidos. In: Contragolpes; seleção de artigos da New Left Review. Org. Emir Sader. São Paulo: Boitempo, 2006. 
diretor acessa ricos arquivos fotográficos e audiovisuais de época ${ }^{82}$, apresentando imagens com o forte racismo de sujeitos brancos, que defendem valores morais e religiosos contra a integração e emancipação negra. É nesta seara que a jovem Dorothy Counts (primeira negra a estudar em escola mista) é apresentada e o fluxo de reminiscência de Baldwin é acessado para falar de como recebeu notícias de sua terra estando em Paris e como julgou necessário sua volta para cumprir seu dever, dar apoio aos seus semelhantes. Com um contra-plano, Peck apresenta propagandas de diversos produtos e serviços que pormenoriza o negro, enfatizando a partir do movimento de câmera a ênfase que deseja dar a cada imagem. Baldwin chama atenção que as diversas paisagens e sensações que povoavam sua mente sobre os Estados Unidos não o faziam sentir falta da terra natal, creditando tão somente a família e as experiências afetivas.

Peck apresenta algumas memórias que forjaram a noção de negritude de Baldwin através de uma nova fonte: filmes, que a partir de sua leitura moldaram sua tenaz critica a sociedade americana. Na sua infância, Baldwin teve contato com o longa "Quando o mundo dança" de H. Beumont (1931), e narra como o filme tratou a beleza da atriz, que aos seus olhos, poderia ser captada também em uma mulher negra. Nestes termos, a inocência de uma criança de sete anos não classificaria de forma distinta a beleza feminina.

Abrindo novo capítulo chamado: "Heróis", Peck trabalha a infância de Baldwin e suas referências, entre elas Bill Miller, professora branca que o apresentou a temas densos da história, bem como a locais culturais como o teatro e cinema, fazendo com que ele não desenvolvesse sentimentos negativos como o ódio ao branco, associando o racismo do homem branco não à sua branquitude, mas a outro motivo ao qual ele não conhecia. Baldwin ressalta sua inocência, bem como o fato de Miller não ser bem vista pelos "senhorios" por sua postura. Enquanto é narrada essa percepção, vemos imagens do King Kong de M. C. Cooper de 1933, em cenas que dão ênfase a uma mulher branca.

Ao citar Richard's Answer (1945) Baldwin chama atenção para representatividade no cinema, tendo como referência o caráter formador que esse meio audiovisual tem para as gerações estadunidenses, observando que os sujeitos negros representados com suas características não eram em nada semelhantes a pessoas ao qual ele conhecia. Baldwin chama atenção para a pormenorização de seu mundo, os personagens das telas não possuíam nenhuma característica

82 É notável o corpus documental que o diretor utiliza, tanto do período segregacionista, bem como do momento atual, dando visibilidade a imagens racistas e a batalha da comunidade negra por afirmação. Raoul Peck mescla a narrativa de Baldwin às imagens dando um sentido biográfico e ao mesmo tempo lírico a sua montagem em Found footage. 
positiva como vistas em seus conhecidos. Em The Monster walks (1932) de F. R. Strayer o medo seria o mais próximo daquilo que ele já vivenciou, a compreensão desta referência fica clara com a seguinte; They Won't forget (1937) de M. Leroy, aqui o personagem lembra o pai de Baldwin, todavia, o personagem vive um suplício que foi marcante para o negro nos Estados Unidos: ser culpabilizado por um crime que não cometeu. Neste filme o zelador negro é suspeito pelo assassinato de uma jovem branca sulista que também fora estuprada, esta imagem, foi imortalizada antes pelo "Nascimento de uma Nação" (1915) de D. W. Griffth que trazia consigo o medo do linchamento, violência comum a negros no país ${ }^{83}$.

Em “A cabana do pai Tomás” (1927) H. A. Pollard traz uma representação do negro que não agrada Baldwin, sem ímpeto, sem uma forte personalidade, ao contrário de "No tempo das diligências" (1939) de John Ford, onde esses atributos são vistos, mas em um sujeito branco. Refletindo assim sua terra, seus heróis, que para Baldwin era motivo de desprezo e temor, para o crítico, era invertido o real valor da ação desses homens, onde um massacre se tornou lenda. Em um contra plano vemos Baldwin proferindo uma fala em Cambridge (1965) alertando que para uma criança negra que cresce vendo rostos brancos, e ao ver esses filmes, torce pelo justiceiro, ao crescer descobre que o índio morto era ele representado, tendo assim uma crise por não se ver como parte da nação ao qual cresceu ${ }^{84}$.

No capítulo seguinte, “Testemunha”, Baldwin narra como conheceu os amigos que elegeu como itinerário de sua obra, a narrativa é feita com imagens documentais da época representando a militância de King, Malcolm e Evers. O crítico assevera que a linha que separa uma testemunha de um ator é tênue, no entanto, real. Não tendo se tornado um seguidor do Islã, ou mesmo dos Panteras Negras, por que não acreditava que todo homem branco fosse um demônio, bem como, um cristão por acreditar que estes não seguiam todos os mandamentos que pregavam, nem mesmo se associou

83 É válido de nota, o episódio que em 1955 levou ao assassinato do jovem negro Emmett Till no Estado do Mississippi, gerando uma onda de comoção e revolta em todo o país. Till, que tinha apenas quatorze anos de idade à época, foi linchado por ter supostamente assoviado para uma mulher branca, dando vazão a mentalidade racista a consumação do pior de todos os crimes: o sexo inter-racial, e mais especificamente, do homem negro com a mulher branca. A indignação com o horror das agressões que marcaram o episódio, agravada pela absolvição dos assassinos por um júri branco, representaram, em meio a tantos crimes, um impulso decisivo para a nacionalização da agenda dos Direitos Civis. Ver: GOULART, Henrique Rodrigues P. O Vigia de O Sol é Para Todos: representações do racismo e das relações raciais sulistas na obra de Harper Lee. Temporalidades, v. 9, p. 217-231, 2017. Recentemente o caso Till foi reaberto, com a confissão de Carolyn Donham de que o garoto nada fez em relação a sua integridade. Ver: FAUS, Joan. EUA reabrem, após 63 anos, caso do assassinato de jovem negro que expôs a brutalidade da segregação racial. Jornal El pais On line. https://brasil.elpais.com/brasil/2018/07/12/internacional/1531418542 061754.html. Acesso em 03/09/18.

84 Muitas destas questões foram trabalhadas também na obra The Devil Finds Work (1976). 
a NAACP ${ }^{85}$ por sua experiência em contato com a associação, que por critério de classe ${ }^{86}$ no norte, o excluiu. Baldwin relata a experiência dos negros no Mississippi, se colocando como alguém que não vivenciou o racismo naqueles termos, e ter observado lhe permitiu ser um cronista de tudo aquilo, uma testemunha.

Baldwin traça as distinções entre o pensamento de Malcolm e King, neste sentido, o primeiro, representante da nação do Islã via King como um Pai Tomas do século XX por sua defesa da filosofia da não-violência, bem como Malcolm era entendido por muitos atores dos direitos civis como um racista. Baldwin delineia um panorama nas respectivas atuações e chega à conclusão de que virtualmente, ao fim de suas vidas eles concordavam bastante um com o outro perante o contexto em que viviam. A história de Lorraine Hansberry é apresentada como mais uma brilhante perda, a autora foi elemento fundamental na pressão de atores pelos direitos civis, Lorraine morreu com apenas trinta e quatro anos. Seguem-se imagens da vida de sujeitos brancos, com uma fala contundente de Baldwin em contra plano que assevera que a segregação se faz, entre outras coisas, pelo fato do homem branco não conhecer a experiência dos negros para além dos espaços compartilhados, desta forma, quando não se identificam como racistas, não possuem necessariamente acesso a experiência do racismo e da segregação que um negro vive, essa fala feita em uma conferencia, possui contra planos com imagens de jovens que perderam suas vidas de forma precoce na atualidade.

Em "Pureza" Baldwin disserta sobre a raiz do ódio. Para os negros, tal sentimento nasce de sua raiva perante o trato que recebe, todavia para o branco, é constituído pelo terror, por todo perigo que o negro pode lhe oferecer. $\mathrm{O}$ crítico analisa neste capítulo como em algumas obras a representação do negro não é sexualizada, bem como é recepcionada de forma distinta nos espaços em que é difundida, para os negros, muitas vezes denota-se um retrocesso, e de forma distinta, para o branco, o negro em uma posição de progresso. Baldwin exemplifica sua analise no mundo da vida, citando uma frase de Bob Keneddy (que tinha chegado aos holofotes a pouco e já ocupava uma boa posição), que asseverou que em quarenta anos havia a possibilidade de um negro chegar a Casa Branca, para Baldwin, os quatrocentos anos de exploração do negro, não poderia esperar mais quarenta para ter uma representatividade.

85 Associação Nacional para o avanço das pessoas de cor. Fundada em 1909, é a mais antiga instituição de luta pela causa dos Negros nos EUA, atuante até hoje.

86 Nestas palavras Baldwin dá pistas à saber de sua pobre infância no Harlem, como filho de uma grande família. Sua trajetória intelectual excepcional pode afastar essa noção pela dificuldade que um negro tinha nos anos 1940-50 para se instruir e tornar-se um intelectual de envergadura como ele se tornou. 
Em "Vendendo o negro" é mostrado a objetificação do cidadão negro e como historicamente lhe foi convertido o papel de propriedade perante a escravidão, para em seguida, de subclasse com a segregação. Peck faz um movimento onde mostra vozes conservadoras quanto ao papel do negro na nação, contrapostas com leituras como a dos Panteras negras. O clima de recrudescimento no país com o passar dos anos é notável na narrativa de Baldwin, as mortes de Evers, Malcolm e King encerram muitas das esperanças. A indústria cultural constrói a ideia de uma democracia que existe apenas no plano do discurso. É nesse contexto que o diretor utiliza o recurso cinematográfico da elipse $^{87}$, trazendo de volta a cena no programa televisivo The Dick Cavet Show, neste momento, acrescentando a fala de um acadêmico branco, o professor de filosofia de Yale Paul Weiss que diz discordar de algumas palavras de Baldwin. Para este, a cor não é um desígnio supremo ${ }^{88}$, exemplificando que Baldwin estaria mais próximo de um escritor branco por suas predileções do que possa lhe parecer, e o mesmo também estaria mais próximo de Baldwin em comparação a um trabalhador braçal branco, não sendo o crivo de cor determinante nestas trajetórias. Por seu turno, Baldwin rebate, alegando diversas experiências, como o terror de viver em uma terra que lhe trouxe a paranoia de ser morto pela cor de sua pele, pela falta de oportunidades iguais em que o negro vive, e que neste sentido, por não viver tais experiências degradantes, não dá acesso ao acadêmico saber o que é ser negro. Fica claro que esta cena é que dá nome a narrativa, a percepção de Baldwin e sua identidade lhe permite dizer ao acadêmico que "ele não é seu negro ${ }^{89 "}$.

A narrativa segue com um tom melancólico e um prognóstico preciso de Baldwin, a América não irá prosperar enquanto não viver plenamente sua cidadania excluindo os negros. Peck utiliza uma montagem com imagens da violência contra os negros nos anos 1960 e em tempos atuais, dando o tom de permanência e de fracasso do desejo de Baldwin. Ao asseverar que a história é o presente, Baldwin fecha sua fala com um desafio, ao mesmo tempo acompanhado de uma centelha de esperança ao dizer que o mundo não é branco, dando um protagonismo ao negro, pois "Branco" é uma metáfora de poder, aqui vemos uma linha do tempo com imagens de sujeitos negros até o nosso tempo em um travelling que demonstra não só a humanidade destes, mas sua diversidade. Peck, ao utilizar um rico material imagético para criar uma obra com grande poder de consciência

87 Retomada de um plano, onde na primeira mostra não é explicitado todo teor de seu significado, com o decorrer da narrativa a compreensão fará/terá maior sentido uma vez que informações para compreensão do plano inicial são de certa forma 'diluídas' na narrativa e fechadas em sua retomada.

88 Aqui fica claro que Paul Weiss possui um discurso que na crítica da jurista Michelle Alexander em seu livro The New Jim Crow chama de Colorblindness. Para a autora, a cegueira da raça é um mecanismo sutil de escamotear o racismo na sociedade americana, implementado no discurso e praticas para driblar as determinações dos Atos por Direitos Civis e de voto dos anos 1960. Ver: ALEXANDER, Michelle. The New Jim Crow: mass incarceration in the age of colorblindness. New Press: New York, 2012.

89 O titulo da obra em inglês: I'am not your negro carrega consigo um simbolismo, o termo 'negro' para a língua 
apresenta cenas da história dos Estados Unidos para todo entusiasta do tema da luta negra. Emparelha sua narrativa com tantas outras que chamam o debate para uma questão latente: o recrudescimento da cidadania negra.

Produções como 12 Anos de escravidão (2012) O Mordomo da casa branca (2014), Libertem Angela Davis (2014), Selma (2014), A 13 Emenda (2016), Estrelas além do tempo (2017), Detroit em rebelião (2017), Get Out (2017), Pantera Negra (2018), tocam, cada um a sua maneira, nas questões vividas pelos negros nos EUA, que no mundo real vive uma violência que mata em larga escala, no último biênio (2015-2016), 508 cidadãos negros foram vítimas da violência policial. Em 2017, a estatística chegou a $258^{90}$. Essa dura realidade diante de um trabalho militante como o de Baldwin, Peck e tantos outros, traz à consciência que o cinema é um campo de batalha pela conscientização da sociedade da importância do combate ao racismo bem como da importância das vidas negras.

\section{Referência documental}

"Eu não sou seu Negro" (I am not your negro). Direção: Raoul Peck, Narração: Samuel L. Jackson. Distribuição: Imovision, Gênero: documentário, EUA, Suíça, França, Bélgica, 2016, 93 minutos, Colorido, Blu Ray.

\section{Referencia Bibliográfica}

ALEXANDER, Michelle. The New Jim Crow: mass incarceration in the age of colorblindness. New Press: New York, 2012.

GOULART, Henrique Rodrigues P. O Vigia de O Sol é Para Todos: representações do racismo e das relações raciais sulistas na obra de Harper Lee. Temporalidades, v. 9, p. 217-231, 2017.

OMI, Michael; WINANT, Howard. "Racial Formations". Racial Formation in the United States: From the 1960s to the 1990s, Routledge, 1994.

PACKARD, Jerrold M. American Nightmare: the history of Jim Crow. New York: St. Martin's Press, 2002.

PLUMMER, Brenda Gayle. (Edit.) Window on freedom; Race, civil rights, and Foreign Affairs, 1945-1988. The University of North Carolina Press, Chapel Hill and London, 2003.

portuguesa diz respeito ao afrodescendente, no inglês possui um tom pejorativo. Se não houvesse essa intenção do autor o 'negro' seria facilmente trocado pelo termo Black, similar ao nosso negro.

90 Disponível em: http://mappingpoliceviolence.org/. Acesso em 12/04/18. 
WACQUANT, Loïc. Da escravidão ao encarceramento em massa: repensando a "questão racial" nos Estados Unidos. In: Contragolpes; seleção de artigos da New Left Review. Org. Emir Sader. São Paulo: Boitempo, 2006.

WOODWARD, C. Vann. The Strange Carrer of Jim Crow. New York: Oxford University Press, 1974. 